\title{
Las comunidades virtuales del quichua ecuatoriano: revalorizando la lengua en un espacio apropiado
}

\author{
As comunidades virtuais do quichua equatoriano: \\ revalorizando a língua em um espaço apropriado
}

Luis Fernando Garcés Velásquez ${ }^{1}$

DOI: http://dx.doi.org/10.20435/tellus.vi43.760

\begin{abstract}
Resumen: Las lenguas indígenas de América tienen una larga historia de subalternización que se mantiene hasta el día de hoy. Por esta razón, las Naciones Unidas declararon el 2019 como el Año Internacional de las Lenguas Indígenas, como un esfuerzo de revertir el proceso de pérdida de la diversidad lingüística del planeta. El quichua ecuatoriano es una lengua con presencia en varios países de la región. En Ecuador es la lengua indígena con mayor número de hablantes; sin embargo, hay evidencias de encontrarse en dramática situación de retroceso en cuanto a la trasmisión intergeneracional. En el contexto actual, los jóvenes quichua hablantes se apropian de recursos tecnológicos para la construcción de comunidades virtuales de defensa y difusión de la lengua y cultura quichua. En esta comunicación, se presenta una investigación de carácter exploratorio de dos comunidades virtuales en el Facebook: Kichwa Mashikuna y Kichwa Hatari NY. A partir de este acercamiento, se postula la necesidad de pensar la supervivencia lingüística de cara a la posibilidad de adaptación al contexto urbano y tecnológico. Y en este sentido, los jóvenes quichuas apuestan a "atravesar la modernidad", antes que rodearla o negarla.
\end{abstract}

Palabras chave: Quichua; Ecuador; Comunidad Andina; comunidades virtuales.

Resumo: As línguas indígenas da América têm uma longa história de subalternização que continua até hoje. Por isso, as Nações Unidas declararam 2019 como o Ano Internacional das Línguas Indígenas, como um esforço para reverter o processo de perda da diversidade linguística no planeta. O quichua equatoriano é uma língua com presença em vários países da região. No Equador, é a língua indígena com maior número de falantes; no entanto, há evidências de uma situação dramática de declínio em termos de transmissão intergeracional. No contexto atual, os jovens falantes do quichua se apropriam de recursos tecnológicos para a construção de comunidades virtuais de defesa e difusão da língua e da cultura quichua. Esta comunicação apresenta uma investigação

${ }^{1}$ Universidad Politécnica Salesiana, Ecuador. 
exploratória de duas comunidades virtuais no Facebook: Kichwa Mashikuna e Kichwa Hatari NY. A partir dessa abordagem, postula-se a necessidade de pensar a sobrevivência linguística diante da possibilidade de adaptação ao contexto urbano e tecnológico. E, nesse sentido, os jovens quichua se comprometem a "passar pela modernidade", em vez de cercá-la ou negá-la.

Keywords: Quichua; Equador; Comunidade Andina; comunidades virtuais.

\section{EL CONTEXTO ACTUAL}

Las lenguas indígenas de Abya Yala, como llaman al continente americano los pueblos y nacionalidades indígenas, han vivido una larga historia de subvaloración y racialización, con distintas intensidades y matices, pero manteniendo el rasgo de subalternización, principalmente desde la instauración del régimen Colonial (Cf. GARCÉS, 2009; RODRÍGUEZ, 2017).

Hoy, las lenguas indígenas del mundo se encuentran amenazadas y bajo el riesgo de privar a la humanidad, entre otros aspectos, de conocimientos complejos en relación a salud, medio ambiente, agricultura, vida en comunidad, etc. (Cf. HARRISON, 2016).

En este contexto, en septiembre del año 2007 la Asamblea General de la ONU aprobó la Declaración sobre los Derechos de los Pueblos Indígenas. En ese documento se dice que "Los pueblos indígenas tienen derecho a revitalizar, utilizar, fomentar y transmitir a las generaciones futuras sus historias, idiomas, tradiciones orales, filosofía, sistemas de escritura y literaturas" (Art. 13, 1). Luego, a partir de estas palabras. la Organización de las Naciones Unidas proclamó el año 2019 como el Año Internacional de las Lenguas Indígenas. El objetivo de esta decisión fue "Ilamar la atención sobre la grave pérdida de las lenguas indígenas y la necesidad apremiante de conservarlas, revitalizarlas y promoverlas y de adoptar nuevas medidas urgentes a nivel nacional e internacional".

En el mundo hay alrededor 7.000 lenguas. Se estima que 210 millones de personas hablan el $96 \%$ de las lenguas del mundo. Esto quiere decir que la minoría de la población habla la mayor cantidad de lenguas diferentes del mundo, mientras la mayoría de la población habla unos pocos idiomas. Los pueblos indígenas hablan más de 4.000 de las 7.000 lenguas (Cf. GARCÉS, 2020). Y de esas 4.000 lenguas indígenas cerca de 2.700 están en peligro de desaparecer. La humanidad, 
entonces, tiene una gran diversidad lingüística, pero es una diversidad amenazada (Cf. HARRISON, 2016).

En el caso de las lenguas indígenas ecuatorianas los datos afirman que todas, incluyendo el quichua, lengua históricamente mayoritaria, se encuentran en franco retroceso. Varios factores inciden en esta triste situación. Rindstedt y Arosson plantean que las dos causas principales de extinción de una lengua son la pobreza y la opresión por parte de la cultura mayoritaria-dominante. Simultáneamente coexisten otros factores como la migración urbana, los desplazamientos, la modernización, la educación en la lengua mayoritaria, etc. ${ }^{2}$ Uno de los factores decisivos es la elección del idioma con que los padres se dirigen a sus hijos (Cf. RINDSTEDT; ARONSSON, 2002).

\section{EL QUICHUA EN ECUADOR}

En el caso específico del quichua, los datos sobre el número de hablantes en el país oscilan entre $591.448^{3}$ y 724.721 (ÁLVAREZ; MONTALUISA, 2017, p. 68) en base al Censo de 2010. ${ }^{4}$ Por otro lado, la comparación de datos entre los censos, muestran la disminución de hablantes en términos absolutos, entre 1950 y 1990, y en términos relativos, entre 1990 y 2001 (Cf. KING; HABOUD, 2002; HABOUD, 2005).

Distintos estudios de grupos diversos confirman los datos de disminución acelerada de hablantes del quichua. Así, según una nota de prensa del Periódico El Norte (de las provincias de Imbabura y Carchi), basada en un estudio de Marleen Haboud,

[...] en el año 90, el $90 \%$ de personas que fueron entrevistadas en un sondeo sociolingüístico, dijo que su lengua materna era el kichwa, mientras que en 2015, menos del $70 \%$ dijo que su lengua propia es el kichwa. Durante un sondeo en estos últimos años, se determinó que de 463 familias entrevistadas, solamente el $30 \%$ reconocieron que hablan el kichwa con sus hijos. ${ }^{5}$

2 Firestone (2017) valora el vínculo de las comunidades inmigrantes urbanas con los territorios rurales como uno de los mecanismos de preservación de la lengua.

3 Véase el Archivo de Lenguas y Culturas del Ecuador, en: https://flacso.edu.ec/lenguas-culturas/ sobre-el-archivo/sobre-lenguas/, consulta del 16/04/2020.

4 Haboud (2005, p. 13) afirma que el quichua "tiene más de 1.000 .000 de hablantes en el país".

5 Véase https://www.elnorte.ec/otavalo/de-463-familias-solo-el-30-habla-kichwa-GJ586800?fb clid=IwAR0xtu2FC9qYppNbPbxGCNbV_5PEOmsA4F3kGqHFImmvZTxxbj4ybWpo3E0, consulta del 03/01/2020. 
De igual forma, a partir de un muestreo sociolingüístico en Salasaca, Mayorga y Haboud afirman que los jóvenes prefieren hablar el castellano; el quichua se usa en las asambleas comunitarias, en las ceremonias tradicionales y para hablar con las autoridades. Así, "En el caso de estudio de la comunidad Salasaca la tendencia de la lengua ancestral [...] es negativa, es decir que las nuevas generaciones cada vez muestran menos preferencia por el uso de la lengua ancestral lo que se agudiza con el uso de nuevas tecnologías" (MAYORGA; HABOUD, 2013, p. 144).

Haboud muestra que ya en la década del 90 había una importante pérdida de uso del quichua en las unidades domésticas de comunidades tradicionalmente consideradas quichuahablantes.

Estudios desarrollados entre 1992 y 1995 sobre el uso del castellano y el quichua en 99 comunidades rurales de 9 provincias de la Sierra, tradicionalmente consideradas quichuahablantes, muestran que aunque en el contexto comunitario el quichua es vital, el alto porcentaje de uso bilingüe (quichua-castellano) a nivel de la unidad doméstica sugiere la pérdida del quichua en el espacio social considerado como la base de la vitalidad de la lengua: la familia. (HABOUD, 2005, p. 25).

Pazmiño, por su parte, informa sobre el estado de vitalidad del quichua en cinco comunidades de cuatro provincias de la sierra ecuatoriana a partir de una encuesta realizada a 80 quichua hablantes. Los resultados muestran las diferencias en la preferencia de uso del quichua y castellano según las edades: los abuelos usaban-conocía-preferían el quichua en un 90\% de casos, mientras los jóvenes, en un 4\% (Cf. PAZMIÑO, 2013, p. 229-30).

El trabajo etnográfico del que dan cuenta Rindstedt y Aronsson en una comunidad de la provincia de Chimborazo es sumamente sugestivo a la vez que dramático. Por un lado, se muestra el quichua como una lengua motivo de orgullo identitario, una lengua con alta valoración discursiva, pero, por otro lado, las autoras señalan un panorama en el que todos los adultos son bilingües; las abuelas hablan quichua "puro puro", mientras el resto de las mujeres hablan en quichua entre sí. Las madres se dirigen a sus hijos en español con algún elemento quichua. El esposo habla a la esposa en quichua y en español, mientras la esposa se dirige a él en quichua. Los padres hablan siempre a los hijos en español y los hermanos mayores a los menores, también en español (Cf. RINDSTEDT; ARONSSON, 2002). 
Lo mencionado por Rindstedt y Aronsson lo he corroborado en mi propio trabajo de etnografía pluritópica y discontinua ${ }^{6}$.

Así, en zonas donde hace 30 años sólo los varones adultos hablaban castellano, hoy en día hay un acentuado bilingüismo y monolingüismo castellano entre los matrimonios jóvenes. En zonas con históricos y contemporáneos discursos reivindicativos indígenas (por ejemplo, Cayambe y Simiatug) se encuentra muy pocas personas mayores de 50 años que hablan la lengua. Ello va de la mano con el hecho que muchos jóvenes tienen un quichua limitado, fruto de no haberlo usado como lengua materna sino de haberlo escuchado en el contexto familiar y, luego, en el proceso de repolitización de la identidad activarlo, pero de manera limitada (no fluida). El factor generacional debe ser relacionado con el de género: en general siguen siendo las mujeres quienes entre ellas hablan más quichua que los varones; por ejemplo, en los mercados urbanos.

En el ámbito escolar, los maestros usan el quichua sólo para saludar al inicio de cada clase, mientras los niños pueden saberlo y usarlo extra-aula, pero no lo usan con los profesores. Por ejemplo, en una de las Escuelas del Milenio de una parroquia de Bolívar, el uso del quichua es meramente simbólico, folclórico y museístico: en las paredes se encuentran escritos en quichua los días de la semana, los meses, las partes del cuerpo, los números, etc.; se usan fórmulas de saludo muy elaboradas: allí puncha mashi yachachik, allí shamushka kachun, pero no se usa como lengua de interacción real en la escuela. Por otro lado, varios estudiantes hablan y entienden el quichua, pero éste se usa en la interacción extra aula.

En cuanto a la valoración lingüística y las expectativas de estudiantes y padres de familia, hay que decir que en muchos lugares la Educación Intercultural Bilingüe, pensada como enseñanza de y en lengua indígena - castellano, se encuentra desprestigiada (HABOUD, 2005). Por contrapartida, en varias comunidades de Cotopaxi, los jóvenes indígenas buscan programas universitarios en los que puedan aprender inglés y "computación". La valoración, sin embargo, está ligada a factores materiales, como el caso de la hija de un reconocido defensor de la EIB que no habla absolutamente nada de quichua debido a que su padre la hizo

\footnotetext{
${ }^{6}$ Realizada a lo largo de 3 años en y con comunidades y hablantes de quichua de las provincias de Cañar, Cotopaxi, Pichincha, Imbabura, Bolívar y Guayas. En el ámbito urbano, específicamente en las ciudades de Quito y Guayaquil.
} 
estudiar en la ciudad de Quito. Lo interesante es que sus hijos tienen nombres quichuas?.

Todo esto indica, al parecer, que el futuro de las lenguas, y para nuestro caso, del quichua, se decidirá en la capacidad que tengan de adaptarse y reproducirse en las ciudades y en la medida en que hablar la lengua y mostrarse como indígena sea un "valor" (como al parecer ahora lo son la vestimenta y la música). Y ello porque, según datos oficiales de las Naciones Unidas y estudios del Banco Mundial alrededor del 50\% de la población indígena de América Latina reside en las ciudades (NACIONES UNIDAS, 2014, p. 158; BANCO MUNDIAL, 2015, p. 30).

Por otro lado, desde la perspectiva de las brechas digitales, es en las ciudades donde se concentra el acceso a tales recursos tecnológicos. La apropiación de los recursos digitales en la sociedad mediatizada contemporánea se da tanto desde los detentadores tecnológicos como desde los sectores subalternos (Cf. MORAES, 2007), de manera que, visto desde esta perspectiva, resulta casi obvio que el quichua pugne por lograr espacios de mantenimiento y revitalización más allá de las políticas lingüísticas, educativas y comunicacionales oficiales del Estado.

\section{COMUNIDADES VIRTUALES DE DEFENSA DE LA LENGUA Y LA CULTURA QUICHUA EN EL FACEBOOK}

El término comunidad es polisémico, por lo que cabe preguntarse qué elementos constituyen aquello que se podría denominar comunidad. En la sociología clásica la comunidad está asociada a "lo duradero", "lo íntimo", "lo auténtico". Su principal característica es la idea de unidad y la posesión y goce de bienes comunes en un terruño específico (Cf. LICEAGA, 2013).

Esta concepción clásica de comunidad habría mutado en las últimas décadas. En la etapa de la modernidad líquida (Cf. BAUMAN, 2002) la comunidad es más una postulación, un proyecto antes que una realidad; es algo que viene después y no antes de la elección individual; en tal sentido, no se trata tanto de un concepto sociológico cuanto de una construcción. Bauman enfatiza la existencia de comunidades extraterritoriales que se caracterizan por ser volátiles, transitorias,

7 El caso de la "cultura" sin lengua lo he tratado en otro lugar (Cf. GARCÉS, 2019). 
mono-aspectadas y mono-propósito, de acontecimiento y espectáculo; en fin, las denomina comunidades guardarropa o de carnaval. De esta forma enfatiza un tipo de asociacionismo no duradero y evanescente típico de la sociedad contemporánea (Cf. BAUMAN, 2002, p. 179-212). En tono nostálgico y de reproche, critica estas comunidades de cara a las "genuinas":

Un efecto de las comunidades de guardarropa/carnaval es impedir la condensación de las "genuinas" (es decir, duraderas y abarcadoras) comunidades a las que imitan y a las que (falsamente) prometen reproducir o generar nuevamente. En cambio, lo que hacen es dispersar la energía de los impulsos sociales y contribuyen así a la perpetuación de una soledad que busca - desesperada pero vanamente-alivio en los raros emprendimientos colectivos concertados y armoniosos. (BAUMAN, 2002, p. 212)

En el ámbito latinoamericano la comunidad suele asociarse a formas de vida rurales, tradicionales y antiguas; suele ir asociada a indígenas y campesinos (LICEAGA, 2013, p. 66). Y en el caso andino, la imagen de la comunidad indígena es que en ella perviven relaciones de solidaridad, reciprocidad y cooperación (Cf. COLPARI, 2011). Más allá de esta visión los trabajos etnográficos contemporáneos dan cuenta de los cambios que han tenido lugar en las comunidades indígenas en las últimas décadas. Así, la investigación de Colpari en la comunidad de Sisid da cuenta del problema del envejecimiento de la población y el abandono de sus habitantes; la ausencia de redes de reciprocidad tales como el trueque, el prestamano, el compadrazo y el priostazgo; el debilitamiento del capital social familiar y la crisis de vinculación con las organizaciones tradicionales; la división del trabajo colectivo y el surgimiento de un capital social negativo (pandillas) (Cf. COLPARI, 2011).

Las comunidades quichuas de la sierra ecuatoriana se enfrentan, entonces, desde por lo menos cuatro décadas, a una serie de transformaciones que cruzan lo económico-productivo, lo organizacional-político, lo representacional, lo cultural; todos aspectos que tienen que ver con procesos de descomunalización e individualización indígena (Cf. SÁNCHEZ-PARGA, 2010). En este contexto, la característica fundamental de la presencia indígena está marcada por la migración y la movilidad, tanto física como laboral, cognitiva y emocional (Cf. GARCÉS, 2019);

8 En el caso de los quichuas de Otavalo, el proceso migratorio empezó hacia la década del 60 del siglo pasado (Cf. ORDÓÑEZ, 2008). 
así mismo, la construcción de nuevas comunidades se vincula a la inserción en el mundo virtual (Cf. RAMíREZ, 2018).

Así,

En plena expansión de Internet las comunidades virtuales se están convirtiendo en un nuevo formato de relación social en el que los diferentes colectivos acuden a ellas para satisfacer unas expectativas o necesidades, para aportar su colaboración y para sentirse parte de un colectivo. (MORENO; SUÁREZ, 2010, p. 2)

En el marco de los sitios de redes sociales, como Facebook, pueden surgir comunidades virtuales, esto es, un determinado número de miembros que se sienten comprometidos entre sí y demuestran un interés común hacia un tema u objetivo concreto (Cf. SANZ, 2011, p. 9).

Desde su creación en 2004 Facebook es la red social virtual de mayor crecimiento en el mundo. Al 2020 tiene más de 2 mil millones de usuarios. Su uso y apropiación sirve para la creación de diversas comunidades virtuales que funcionan, entre otras cosas, como espacios de activismo social y político (Cf. RAMíREZ, 2018), por un lado, y cultural y lingüístico (Cf. LE MUR, 2018; CRU, 2015), por otro.

En lo que sigue quisiera presentar un trabajo exploratorio sobre dos comunidades virtuales de defensa cultural y lingüística quichua: Kichwa mashikuna9 , y Kichwa Hatari $\mathrm{NY}^{10}$, ambas de visibilización y articulación a través de la red Facebook. La primera se gestiona desde la provincia de Imbabura y la segunda desde la ciudad de Nueva York. Hemos hecho un seguimiento, a manera de una etnografía digital (Cf. PINK et al., 2019), durante los meses de febrero, marzo y abril de 2020. Presentaremos algunos ejemplos del uso del quichua y de enunciados a favor del mismo.

Kichwa mashikuna es un grupo creado el 18 de febrero de 2015 y al 18 de abril de 2020 tenía 3.274 miembros.

En el grupo de publican textos y videos de distinta naturaleza y temática: poesías, canciones, eventos en vivo, comunicados, mensajes de autoayuda, etc. A manera de ejemplo, presento el texto de José Luis Maigua, quien postea el texto: "Imata pasan paloma / Karaway nikpi karani / Maki huntata kunika / Chayllachu

\footnotetext{
${ }^{9}$ Literalmente, 'amigos / compañeros quichuas'.

10 Literalmente, "Levantar el quichua de Nueva York".
} 
karka niwanki / ii iAay karaju!!! (José Luis Maigua, 17/02/2020). [Qué pasa paloma. Me dijiste que te regalara, por eso te doy (amor). Te doy mano llena. Esito nomás sería... me dices] (Traducción proporcionada).

Imagen 1 - Página de presentación de Kichwa Mashikuna en el Facebook

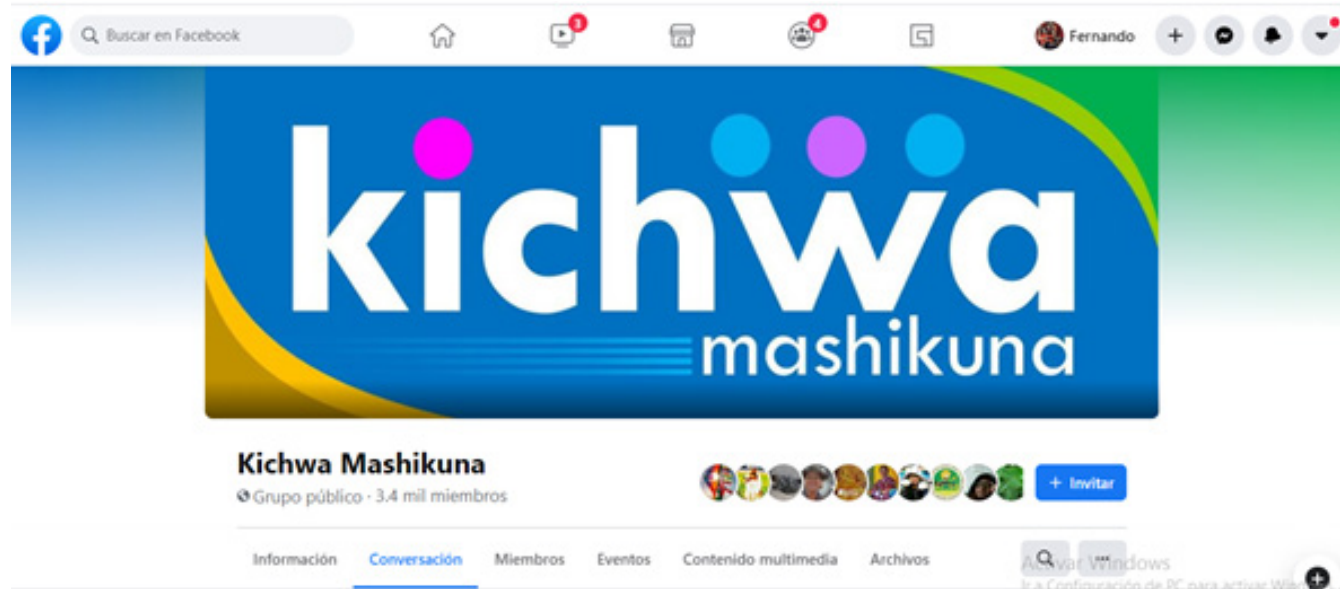

Fuente: https://www.facebook.com/groups/749828998458070, acceso en 27/04/2020

En términos de revitalización lingüística es importante la interacción con los miembros del grupo. Por ejemplo, Fabian Ch pregunta cómo se debe escribir en quichua "Gotas de lluvia", si tamya shutuy o tamya shutuna (17/02/2020). Así mismo, Luispolo Maldo (19/02/2020) escribe: "Imanalla mashis como se dice, pensar con el corazón, Yupaychani mashis". Entre las varias respuestas que destacan tenemos: Shunkumi yuyani (Brayan Jinde) y Yuyarini Shunkuwa (Alis Chimbo).

Me detengo en aquellos aspectos que revelan una opción por la reivindicación lingüística y cultural. Así, en la información que describe al grupo se afirma:

Kichwata kuyak mashikunapa zirma panka kan. Kaypimi tukuy kichwapi shuyukunata, kuyukshuyukunata, killkashkakunata churana kapankichik. Kichwapi rurashkatami ashtawan chaskishpashun. Ama shinaku kashpa KICHWAPILLA Mashikuna. ${ }^{11}$

[Es una página electrónica de los amantes del quichua. Aquí podemos poner todas las imágenes, videos, textos en quichua. Recibimos noticias de

\footnotetext{
${ }^{11}$ En: https://www.facebook.com/groups/749828998458070, consulta del 07/04/2021
} 
acontecimientos en quichua. Cualquier información SÓLO EN QUICHUA, amigos] (Traducción mía).

Al igual que la otra comunidad, como veremos, a partir del 7 de marzo se publicaron casi diariamente mensajes, avisos, recomendaciones en quichua sobre el COVID-19. Por ejemplo, el 21 de marzo se presenta un informativo totalmente en quichua dando cuenta de la situación (número de contagiados y fallecidos) tanto en el país como en Italia.

El grupo también hace eco de otras publicaciones conectadas con el mismo tema, pero desde otras latitudes. Así, el 12 de abril Victoriano Teposteko comparte una publicación que dice: "Si estás en casa con tu familia y hablan una lengua Originaria, es hora de usarla. No hay pretextos". Y abajo, a manera de firma: "Yolitia Totlahtol Jalisco".

A partir del 14 de abril se puede encontrar varios videos de \#FamiliaChallenge y de \#RunaChallenge como una versión local del \#dontrushchallenge. Se trata de un desafío en el que los jóvenes y niños/as indígenas cambian prendas de vestir mestizas por su prenda de vestir indígena ${ }^{12}$. En los distintos videos participan indígenas de Imbabura, Cañar, Loja, Pichincha.

La página Kichwa Hatari NY, fue creada el 3 de noviembre de 2017 y al 20/04/2020 tenía 5.925 seguidores. Aquí también se puede encontrar información de diferente tipo-formato (comunicados, noticias, entrevistas, conversatorios, etc.), bajo distintos soportes (video, texto, imagen) y temporalidades (transmisión en vivo y diferida).

\footnotetext{
12 Puede consultarse, sólo a manera de ejemplo: https://www.facebook.com/carina.chacaguasay/ videos/2615558078572681/UzpfSTEwMDAwMjMOMjlzMjYzMjpWSzoyODgzMDEOMzYxOD A2MTc5/?epa=SEARCH_BOX. También: https://www.facebook.com/malku.longpause/videos/10222271372356552/UzpfSTEwMDAwNjczNjU0MTgzNTpWSzoyODg1MjU1ODE4MjQ4Nz Aw/?epa=SEARCH_BOX.
} 
Imagen 2 - Página de presentación de Kichwa Hatari NY en el Facebook

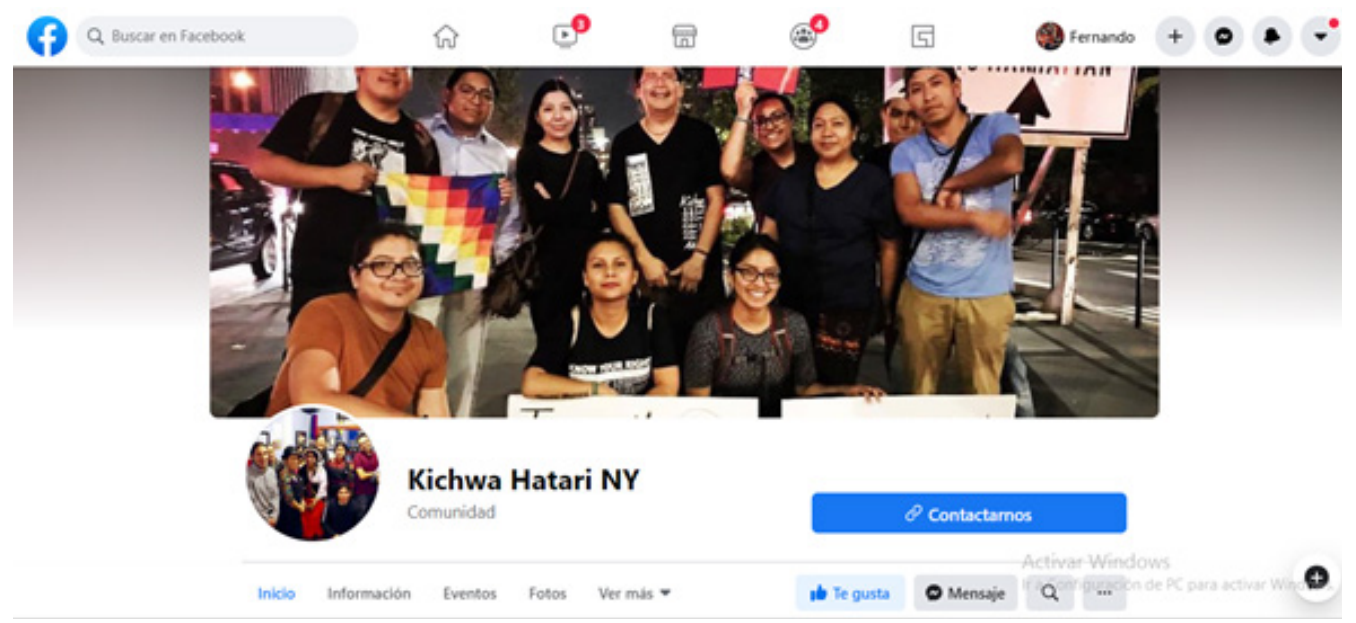

Fuente: https://www.facebook.com/KichwaHatari, acceso en 27/04/2020.

El colectivo que gestiona la página se define así:

Kichwa Hatari tantanakuyka Estados Unidos Mama Llaktapi kawsak Kichwa Runa mashikunami kanchi. Ñukanchikka yachakukkuna, shuyukkuna, arawik killkakkuna, wayra-antapi rimakkuna, yachachikkunapashmi kanchi. Shinami ñukanchik llankaykunawan punkukunata paskashpa, ñukanchik mashikunata yachachishpa, shuktik tantanakuykunawan makipurarishpa, Runa kawsayta, shimita, tantanakuykunata sinchiyachinkapan wacharishkanchi.13

[El colectivo Kichwa Hatari está conformado por indígenas residentes en Estados Unidos. Somos estudiantes, pintores, escritores, comunicadores, profesores. Así, con nuestro quehacer abrimos las puertas, enseñando a nuestros compañeros otros tipos de organización y convivencia. Hemos nacido para fortalecer las organizaciones, la lengua y la cultura] (Traducción mía).

El colectivo gestiona también la Radio digital Tambo Stereo y dentro de ella el programa Kichwa Hatari, lugar en el que se generan entrevistas, diálogos e insumos para la página en general. La cortina de identificación del programa dice lo siguiente:

Ñukanchik kawsaymanta, ñukanchik kichwa rimaymanta karupi kashpapish mana manchashpa shuk shunkulla shuk yuyaylla shuk makilla shuk

13 En: https://www.facebook.com/KichwaHatari/about, consulta del 07/04/2021. 
shimilla kawsankapak kaypimi kan kichwa hatari. Uyashunchik, shinashpaka kichwashun. ${ }^{14}$

[Nuestra cultura, nuestro hablar kichwa, estando lejos no hay que asustarse: un corazón, un pensamiento, una mano, una voz; para vivir aquí está Kichwa Hatari. Escuchemos y quichuemos] (Traducción mía).

Aquí también la coyuntura del Coronavirus marca la intensidad de la comunicación desde el mes de marzo. No obstante, a diferencia de Kichwa mashikuna esta página toca temas específicos para los migrantes. Por ejemplo, la Convocatoria para la Juve Expo, la tarjeta de identidad y el Censo 2020.

El 25 de febrero se posteó un poster bilingüe (quichua y castellano) en el que se convoca a una reunión para el sábado 29 de febrero con el objetivo de integrar la comunidad hispana. La versión quichua del póster, aparte de los datos indicativos de fecha y hora, invita a los jóvenes a formar la organización Juventud Ecuatoriana, para estar más cerca de su tierra (Kikin llaktaman kuchulla kapay), a partir de una serie de acciones a programar para al año 2020.

El 15/02/2020 se subió un video en el YouTube (posteado el 26 de febrero) en que se da las instrucciones para obtener la IDNYC (tarjeta de identidad para los habitantes de NY). Se indica que nadie les va a preguntar de dónde son o quiénes son. Se dice que la tarjeta servirá para la realización de trámites escolares, comerciales y para sacar la licencia de conducir. Se enfatiza que no hay que preocuparse del hecho de sacar la tarjeta; en ella se puede dar la información que uno desea. Además, se puede obtener por computadora. El video, totalmente en quichua, termina diciendo: "Nueva York kitika tukuykunapakmi kan" [Nueva York es una ciudad para todos].

En un video del 26 de marzo aparecen 3 personas sentadas una junto a otra (Fabian M. de Otavalo, Deysi P. y Segundo A. de Cañar). Todos vestidos con sus prendas indígenas. Se actúa un diálogo con el fin de informar sobre el censo. Fabián les pregunta si saben qué es el censo del 2020. Los dos le dicen que no saben. Fabián dice que en EEUU va a haber un nuevo censo y todos los que viven allí van a ser contados: los nacidos ahí y los que han venido de otros lugares. Enfatiza que hay

\footnotetext{
${ }^{14}$ Este mensaje está en la cortina de identificación de todos los programas. A manera de ejemplo puede escucharse en: https://www.facebook.com/KichwaHatari/videos/789709341675796, consulta del 07/04/2021.
} 
que hacerse censar para no perder la oportunidad de mejores condiciones de vida: escuelas, hospitales. Hasta ahora, dice, estamos viviendo como olvidados; tenemos que juntarnos para ver cómo queremos vivir como runas aquí en Estados Unidos. Ante la pregunta de quién les va a ayudar a hacer el censo, Fabián les indica que hay 3 formas: 1) Ilenando cada uno las hojas que enviarán a sus casas; 2) Ilenando el formulario que está disponible en la computadora; 3) pidiendo ayuda para que vengan a casa los del censo. Deysi pregunta si hay algún problema con el hecho de ser inmigrante. Fabián contesta que no hay que tener miedo, que el censo es para mejorar la forma de vida de los habitantes del país, igual que chinos, rusos, etc. con sus lenguas y culturas. Además, los datos son privados; no se divulgan fuera del país.

Finalmente, Rumiñahui Cachimuel postea, el 02/03/2020, un video de la intervención Ninari Chimba Santillán en el Congreso Internacional de lenguas en riesgo. Ella empieza diciendo: "Waranka waranka kutin tikramushun, nirka ñukanchik hatun mamakuna hatun taytakunapash. Ima munanchik, ima muskunchik, ñukanchik shimikuna ama wañuchun". [Miles y miles volveremos, dijeron nuestras abuelas y abuelos. Lo que queremos y lo que soñamos es que no mueran nuestras lenguas]. Luego de estas palabras, su alocución es en castellano. En ella dice que, bajo el privilegio de hablar español, "Venimos acá a decir desde el corazón por qué tenemos que seguir hablando nuestra lengua, por qué tenemos que seguir encariñándonos [con ella]".

\section{CONCLUSIÓN}

Las lenguas indígenas del Continente tienen una larga historia de subalternización lingüística. Como hemos visto, ello atinge también al quichua ecuatoriano, lengua indígena tradicionalmente mayoritaria en el país, que hoy se encuentra en franco retroceso. Por otro lado, hemos visto que la comunidad andina, lugar por excelencia de uso y reproducción del quichua, se encuentra en proceso de transformación. La migración a los ámbitos urbanos y el acceso a los medios digitales crean nuevas comunidades habitadas por quichua hablantes.

En tal contexto, las redes sociales virtuales son espacios apropiados: los quichuas, en general, y los jóvenes, de manera específica, se apropian de la tecnología digital, tal como en su momento se apropiaron de otras tecnologías: la escritura, la formulación legal, la enseñanza en contextos formales, etc. 
Un aspecto interesante a destacar es que, gracias a la multimodalidad, los espacios virtuales de las comunidades permiten articular, oralidad-gestualidad- visualidad en distintos niveles e intensidades. Y ello ocurre por fuera del carácter normativo y colonial que tuvo la escritura alfabética. Este aspecto, además, está relacionado con la necesidad de posicionar la lengua transterritorialmente, lo que facilita las posibilidades conectivas de los quichuas dispersos por el mundo.

En general, la mayoría de los estudios sociolingüísticos enfatizan que la migración a la ciudad, el acceso a la tecnología y la modernidad serían causales de pérdida lingüística. Y ello se lo señala en tono de lamento y nostalgia por el pasado territorial prístino. Los procesos de urbanización y de incremento de acceso a la tecnología son irrefrenables. Por tanto, las lenguas sobrevivirán si logran adaptarse al ámbito urbano, tecnológico y moderno. Y no sólo ello: si logran adaptarse a esos ámbitos desde el contexto global que ahora habitan.

El desafío de los pueblos indígenas, hoy, no consiste en retornar a pasados gloriosos, aunque tal búsqueda sea comprensible y discursivamente necesaria. El desafío de pueblos, nacionalidades y lenguas, consiste en reproducir y adaptar valores, prácticas y asociaciones atravesando la modernidad, no rodeándola o negándola (Cf. CASTRO-GÓMEZ, 2019, p. 7-16; PRATT, 2010, p. 421).

A ese desafío se están enfrentando los jóvenes quichuas, con todas las potencialidades y riesgos que ello implica.

\section{REFERENCIAS}

ÁlVAREZ, Catalina; MONTALUISA, Luis. Perfiles de las lenguas y saberes del Ecuador. Quito: IICSAE, 2017.

BANCO MUNDIAL. Latinoamérica indígena en el Siglo XXI. Washington: Banco Mundial, 2015.

BAUMAN, Zygmunt. Modernidad líquida. México: FCE, 2002. [3. reimpr., 2004].

CASTRO-GÓMEZ, Santiago. El tonto y los canallas: notas para un republicanismo transmoderno. Bogotá: Pontificia Universidad Javeriana, 2019.

COLPARI, Otto. ¿La muerte de la comunidad? Estudio de la des-estructuración del capital social de la comunidad indígena Sisid. 2011. Tesis (Maestría en Ciencias Sociales con mención en Desarrollo Local y Territorio) - FLACSO, Sede Ecuador, Quito, 2011. 
CRU, Josep. Bilingual rapping in Yucatán, Mexico: strategic choices for Maya language legitimation and revitalization. International Journal of Bilingual Education and Bilingualism, v. 20, n. 5, p. 481-96, 2015. Disponible: http://dx.doi.org/10.1080/136700 50.2015.1051945. Acceso en: 17 jul. 2018.

FIRESTONE, Amy. Combinamos el quechua: lengua e identidad de los jóvenes urbanos en el Perú. Lima: IEP, 2017.

GARCÉS, Fernando. La revitalización de las lenguas indígenas del Ecuador: una tarea de todos. Quito: UPS, 2020.

GARCÉS, Fernando. "Soy de aquí y soy de allá": un ejercicio de reflexión sobre identidades, lenguas y territorios desde el quichua ecuatoriano. En: ARRATIA, Marina; LIMACHI, Vicente (Org.). Construyendo una sociolingüística del Sur: reflexiones sobre las culturas y lenguas indígenas de América Latina en los nuevos escenarios. Cochabamba: PROEIB; Andes: UCL, 2019. p. 13-2

GARCÉS, Fernando. ¿Colonialidad o interculturalidad? Representaciones de la lengua y el conocimiento quechuas. La Paz: PIEB; UASB, 2009.

HABOUD, Marleen. Quichua ecuatoriano: entre el poder simbólico y el poder real. En: Hella Olbertz y Pieter Muysken (Coord.). Encuentros y conflictos: bilingüismo y contacto de lenguas en el mundo andino. Madrid: Vervuert/Iberoamericana, 2005. p. 13-38.

HARRISON, David. Cuando mueren las lenguas: La extinción de los idiomas en el mundo y la erosión del conocimiento humano. Bogotá: Universidad de los Andes, Instituto Colombiano de Antropología e Historia, 2016.

KING, Kendall; HABOUD Marleen. Language Planning and Policy in Ecuador. Current Issues in Language Planning, v. 3, n. 4, p. 359-424, 2002.

LE MUR, Rozenn. El uso de aplicaciones digitales para divulgar las lenguas indígenas en México. En: PLASCENCIA, David Ramírez (Coord.). Aperturas digitales: apropiación y uso de tecnologías digitales entre grupos étnicos minorizados en México. Guadalajara: Universidad de Guadalajara, 2018. p. 43-58.

LICEAGA, Gabriel. El concepto de comunidad en las ciencias sociales latinoamericanas: apuntes para su comprensión. Cuadernos americanos, n. 145, p. 57-85, 2013.

MAYORGA, Olga; HABOUD, Marleen. GeolinguisticaEcuador: un estudio interdisciplinario sobre la vitalidad de las lenguas ancestrales del Ecuador. En: HABOUD, Marleen; OSTLER, Nicholas. Voces e imágenes de las lenguas en peligro. Quito: Abya Yala/PUCE, 2013. p. 137-44. 
MORAES, Dênis (Coord.). Sociedad mediatizada. Barcelona: Gedisa, 2007.

MORENO, Almudena; SUÁREZ, Carolina. "Las comunidades virtuales como nuevas formas de relación social: elementos para el análisis" en Espéculo. Revista de estudios literarios, XIV: 43, 2010. Disponible: http://www.ucm.es/info/especulo/numero43/covirtual.html. Acceso en: 2 mar. 2020.

NACIONES UNIDAS. Los pueblos indígenas en América Latina: avances en el último decenio y retos pendientes para la garantía de sus derechos. Santiago de Chile: Naciones Unidas, 2014.

ORDÓÑEZ, Angélica. Migración transnacional de los kichwa otavalo y la fiesta del Pawkar Raymi. En: TORRES, Alicia; CARRASCO, Jesús (Ed.). Al filo de la identidad: la migración indígena en América Latina. Quito: FLACSO/UNICEF/AECID, 2008. p. 68-89.

PAZMIÑO, Alliwa. Sondeo de vitalidad de la lengua kichwa en comunidades serranas. En: HABOUD, Marleen; OSTLER, Nicholas (Ed.). Voces e imágenes de las lenguas en peligro. Quito: Abya Yala/PUCE, 2013. p. 227-31.

PINK, Sarah; HORST, Heather; POSTILL, John; HJORTH, Larissa; LEWIS, Tania; Jo TACCHI. Etnografía digital: principios y práctica. Madrid: Morata, 2019.

PRATT, Mary Louise. Ojos imperiales: Literatura de viajes y transculturación. México: FCE, 2010.

RAMÍREZ, David. Un acercamiento a los estudios sobre apropiación y usos de tecnologías digitales entre grupos étnicos minorizados en México. En: PLASCENCIA, David Ramírez (Coord.). Aperturas digitales: Apropiación y uso de tecnologías digitales entre grupos étnicos minorizados en México. Guadalajara: Universidad de Guadalajara, 2018. p. 10-7.

RINDSTEDT, Camilla; ARONSSON, Karin. Growing up monolingual in a bilingual community: the Quichua revitalization paradox. Language in Society, n. 31, 2002. p. 721-42.

RODRÍGUEZ, Adriana. El largo camino del Taki Unkuy: los derechos lingüísticos y culturales de los pueblos indígenas del Ecuador. Quito: U. de Cuenca/Huaponi Ediciones, 2017.

SÁNCHEZ-PARGA, José. Qué significa ser indígena para el indígena. Más allá de la comunidad y la lengua. Quito: UPS; Abya Yala, 2010.

SANZ, Sandra. Comunidades virtuales. Barcelona: UOC, 2011. [Módulo 2 del curso Redes Sociales y Comunidades Virtuales] 


\section{Sobre el autor:}

Luis Fernando Garcés Velásquez: Doctor en Estudios Culturales Latinoamericanos. Docente titular principal de la Universidad Politécnica Salesiana, Ecuador. E-mail: Igarcesv@ups.edu.ec, ORCID: https://orcid.org/0000-0002-0059-4932

Recibido el 3 de octubre de 2020.

Aprobado para su publicación el 3 de noviembre de 2020. 
